\title{
Comparative Analysis of Ejector Refrigeration System Powered with Engine Exhaust Heat using R134a and R245fa
}

\author{
Alper Yılmaz ${ }^{1}$, Arif Emre Aktaş ${ }^{1 *}$ \\ ${ }^{1}$ Çukurova University, Engineering Faculty, Department of Automotive Engineering, Adana, Turkey \\ ORCID: A. Yllmaz (0000-0002-4644-3582), A.E. Aktaş (0000-0002-6017-9917)
}

\begin{abstract}
An ejector refrigeration (ER) system using exhaust waste heat of a heavy vehicle engine is investigated. A program is developed using engineering equation solver software and it is used to make the calculations of the system. The system is taking all the efficiencies of system's components into account. Refrigerants R134a and R245fa are used for the comparative simulation of the system. The pressure at the exit of the pump is varied from 6 to $14 \mathrm{MPa}$ and 3 to $10 \mathrm{MPa}$ for R134a and R245fa, respectively. It can be concluded that COP (coefficient of performance) of the system gradually increases with the increase in pump exit pressure. Results show that, the performance of the system would be higher if R245fa is preferred rather than R134a with the given operating conditions.
\end{abstract}

Keywords: COP, ejector refrigeration, heavy vehicle, air conditioning.

\section{INTRODUCTION}

In recent years, air conditioning application is rapidly growing in automotive industry due to the increased human thermal comfort need. Required energy is supplied from the engine. Thus, it causes additional fuel consumption. On the other hand, almost $70 \%$ of the fuel energy is released to the atmosphere as a waste heat [1]. Waste heat driven ejector refrigeration system is one of the best promising way to obtain air conditioning. Therefore, many researchers are involved in searching the ways to improve the cooling performance of ER systems

Dong et al. performed an experimental analysis of ejector refrigeration system using low temperature heat sources. Results proved that, ejector refrigeration can successfully be carried out at the generator temperatures between $40^{\circ} \mathrm{C}$ and $70^{\circ} \mathrm{C}$. Study also showed that lower temperatures give higher COP [2].

Chen et al. carried out a theoretical study on two stage compression cooling cycle using R717 as working fluid. First stage is realized by a mechanical compressor and second one is realized by an ejector. The effect of pressure and condensing/evaporating temperatures on the system performance is inspected. Results revealed that about $34.5 \%$ less power consumption can be obtained with the given two stage cycle as a substitute for vapor compression cycle [3].
Ünal et al. performed experimental and theoretical optimization study on two phase ejector refrigeration system for bus air conditioning using R134a as refrigerant. The influence of condensation and evaporation is inspected. According to results, $55 \%$ and $4 \%$ of heat transfer surface area can be reduced for evaporator and condenser, respectively [4].

Khaliq introduced a refrigeration system which is a combination of ejector expansion Joule-Thomson cooling cycle and ejector-absorption refrigeration cycle powered by waste heat [5].

Zhang et al. presented a new electronic expansion valve based ejector for domestic cooling applications. In order to determine the optimum geometric parameters of the model computational fluid dynamic simulations (CFD) were applied to the proposed cycle. At optimum conditions, area ratio and length of the fixed area mixing room, which are the two critical parameters, were determined as 7.29 and $5 \mathrm{~mm}$, respectively [6].

In this paper, ejector refrigeration system is studied at moderate generator temperatures at the ranges of $130-210{ }^{\circ} \mathrm{C}$. utilizing heavy vehicle waste exhaust gases. Wet refrigerant R134a and dry refrigerant R245fa are selected as working fluids. Both refrigerants have 0 ODP (ozone depletion potential), low toxicity and high resistance to flame. Ejector inlet temperature and pressure are selected so that vapor-liqu- 
id two-phase flow could not originate in the ejector.

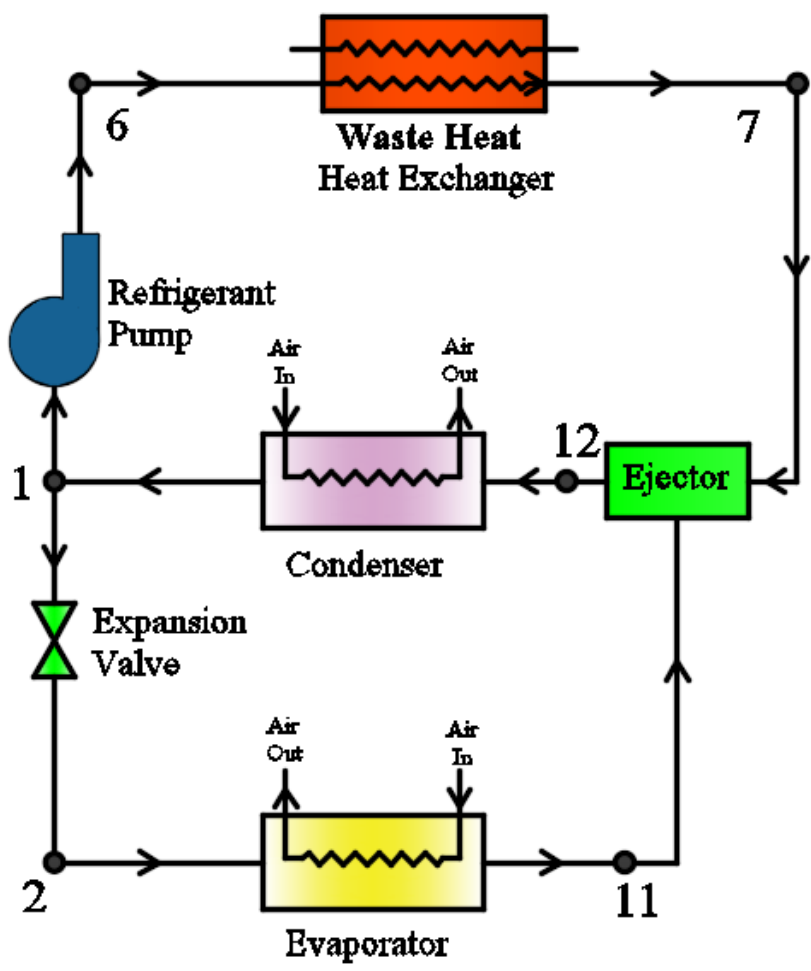

Figure 1. Schematical presentation of ejector refrigeration system

\section{EJECTOR REFRIGERATION SYSTEM}

Ejector refrigeration system and the ejector itself are schematically drawn in figure 1 and 2, respectively. The system cycle is demonstrated in a P-h diagram in figure 3. Refrigerant is pressurized from condensation pressure at point 1 to a pressure of $\mathrm{P}_{6}$ which is higher than critical pressure. In case of isentropic compression, the state obtained after the pump is point 5 . In the generator, refrigerant is heated up to temperature $T_{7}$ below the exhaust gas inlet temperature. High pressure and heated refrigerant enters the ejector's nozzle and leaves it at the evaporation pressure $\mathrm{P}_{3}$ at point 9 $\left(\mathrm{P}_{3}=\mathrm{P}_{9}\right)$. If isentropic expansion is assumed in the nozzle of the ejector, point 8 would be reached. This vapor at point 9 and the vapor leaving the evaporator at point 11 are mixed at point 10 and then elevated to the condenser pressure $P_{14}$ at point $12\left(\mathrm{P}_{14}=\mathrm{P}_{12}\right)$ in the diffuser. Assuming isentropic compression in the ejector's diffuser, state 13 would be reached. After condensation at point 1 , certain portion of the refrigerant enters into the expansion valve and then into the evaporator to obtain cooling at the temperature of evaporator between the points 2 and 11 . Rest of the refrigerant that leaves the condenser enters into the pump and the cycle is repeated. The power and the refrigeration cycles are investigated with the thermodynamic analysis below. Refrigerant is heated using the heat exchanger which transfer heat from engine exhaust waste gas.

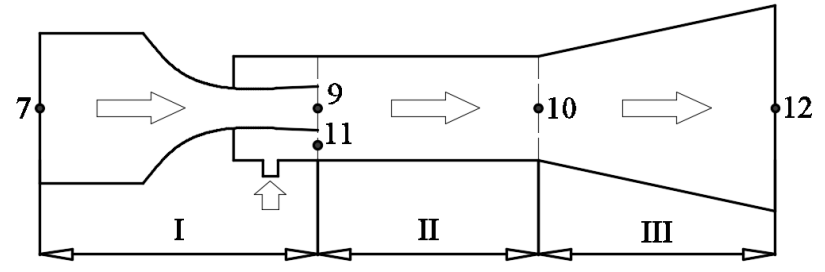

Figure 2. Ejector, I: Nozzle, II: Mixing Room, III: Diffuser.

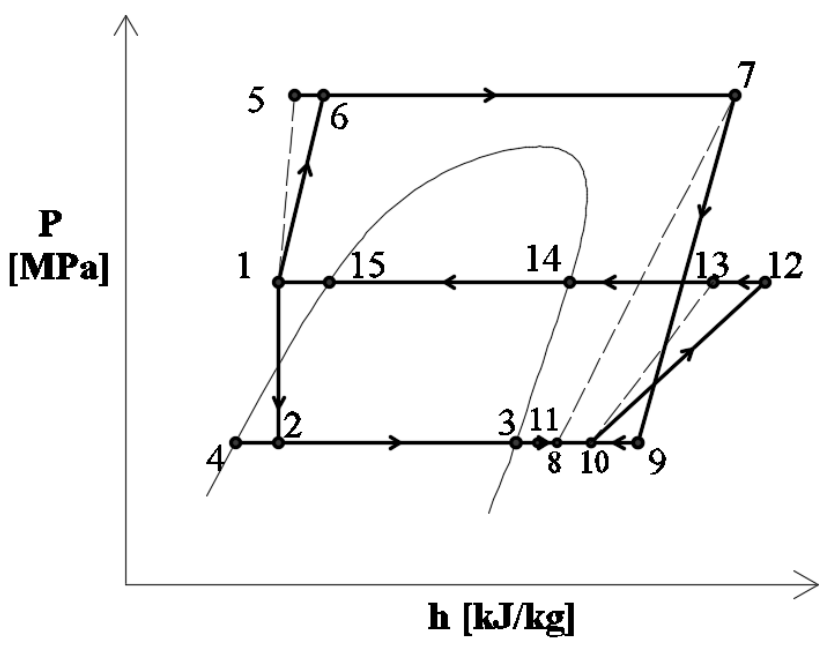

Figure 3. Pressure - enthalpy diagram of ejector refrigeration system

\subsection{Thermodynamic Analysis}

In air-conditioners, the main parameter that determines the evaporation temperature is the inlet temperature of air to be cooled. Working fluid temperature $\mathrm{T}_{2}$ can be assumed to be $10-15{ }^{\circ} \mathrm{C}$ below air inlet temperature that is to be cooled dependent on the evaporator. By air-conditioning, dehumidifying must also be taken into consideration. $\mathrm{T}_{2}$ is assigned taking these factors into account. Moreover, condensation temperature $T_{15}$ is also given dependent upon inlet air temperature of the condenser.

For the analysis, isentropic efficiency of the pump $\eta_{p i}$, total mechanical, coupling and electromotor efficiencies of the pump $\eta_{p m e}$ must also be supplied. All those efficiencies are assumed as constant. Besides them, electricity production efficiency $\eta_{e}$ from heat energy is needed. In the ejector, primary nozzle isentropic efficiency $\eta_{n}$ and diffuser isentropic efficiency $\eta_{d}$ are also required. It is also necessary to give the value of the mixing efficiency $\eta_{m}$ in the ejector.

Table 1. Ejector and pump isentropic efficiency values

\begin{tabular}{|c|c|c|c|}
\hline \multicolumn{3}{|c|}{ Ejector Efficiencies } & Pump Isentropic Efficiency \\
\hline$\eta_{n}$ & $\eta_{m}$ & $\eta_{d}$ & $\eta_{p i}$ \\
\hline 0.90 & 0.90 & 0.875 & 0.825 \\
\hline
\end{tabular}

In different works, efficiencies of vapor ejectors are investigated [7-14]. Different primary nozzle isentropic efficiencies, diffuser isentropic efficiencies and mixing efficiencies are investigated and mean values of them are determined and given in table 1. Pump isentropic efficiencies [11,14-17] are also given in this table.

Condenser and evaporator pressures are obtained using condenser and evaporator temperatures that are given, Be- 
cause temperature differences for subcooling $\Delta T_{S C}$ and superheating $\Delta T_{S T}$ are given, condenser exit temperature $\mathrm{T}_{6}$ and evaporator exit temperature $\mathrm{T}_{11}$ can be determined. After the pump, point 5 is stated for isentropic compression. This point can be determined from:

$$
\begin{aligned}
& S_{5}=S_{1} \\
& P_{5}=P_{6}
\end{aligned}
$$

Pressure P6 is given as parameter for the calculations.

Afterwards, one can determine the real point 6 from the isentropic pump efficiency definition:

$$
\eta_{p i}=\frac{h_{5}-h_{1}}{h_{6}-h_{1}}
$$

Point 7 can be determined using the temperature after the heater. Heated and pressurized fluid at point 7 enters the ejector's nozzle. The refrigerant vapour after the evaporator at point 11 enters into the ejector at the suction part. These two streams are mixed at point 10 and then the refrigerant leaves the ejector at point 12 which is the inlet condition of the condenser.

At the nozzle's exit, pressure is assumed to the evaporator pressure:

$$
P_{8}=P_{9}=P_{11}
$$

The isentropic nozzle efficiency $\eta_{n}$ is defined as follows:

$$
\eta_{n}=\frac{h_{7}-h_{9}}{h_{7}-h_{8}}
$$

$\mathrm{h}_{13}$ is the enthalpy at the exit of the nozzle in case of isentropic process. Therefore,

$$
S_{8}=S_{7}
$$

From these equations, one can find point 9, where the velocity is determined from energy equation between point 7 and 9 with the neglection of the kinetic energy at the nozzle inlet at point 7:

$$
u_{9}=\sqrt{2\left(h_{7}-h_{9}\right)}
$$

Energy equation at points 7, 11 and 10 yields:

$$
h_{7}+w \cdot h_{11}=(1+w)\left(h_{10}+\frac{u_{10}^{2}}{2}\right)
$$

Here, the entrainment ratio is given by:

$$
w=\frac{\dot{M}_{11}}{\dot{M}_{7}}
$$

$\dot{M}_{7}$ and $\dot{M}_{\mathbb{1}}$ are primary fluid's mass flow rates at point 7 from the heat exchanger and secondary fluid's at point 11 from the evaporator. Using the momentum equation between nozzle exit and the end of the mixing region (point 10), one obtains the following equation with introducing mixing efficiency $\eta_{m}[14]$ :

$$
u_{10}=\frac{u_{9}}{1+w} \sqrt{\eta_{m}}
$$

In the mixing region, constant pressure and constant cross-sectional area are assumed. Isentropic diffuser efficiency is defined as follows:

$$
\eta_{d}=\frac{h_{13}-h_{10}}{h_{12}-h_{10}}
$$

Here, point 13 is isentropic compression point at the end of the diffuser. It can be found from:

$$
\begin{aligned}
& S_{13}=S_{10} \\
& P_{12}=P_{13}
\end{aligned}
$$

From the energy equation between the points 10 and 12, it follows:

$$
h_{12}=h_{10}+\frac{u_{10}^{2}}{2}
$$

Expansion from 1 to 2 is assumed to occur at constant enthalpy and therefore, the following expression can be written:

$$
h_{2}=h_{1}
$$

Because superheating at the evaporator exit is given, point 11 can be determined from the given evaporator temperature.

$$
C O P=w \frac{h_{11}-h_{2}}{h_{4}-h_{6}}
$$

\section{RESULTS AND DISCUSSION}

In mobile systems, summer air-conditioning indoor and outdoor design temperatures are taken as $25^{\circ} \mathrm{C}$ and $35^{\circ} \mathrm{C}$, respectively $[19,20]$. Evaporation temperature of refrigerant is selected as $10{ }^{\circ} \mathrm{C}$ to compensate for the dehumidification duty of the air-conditioning unit. Moreover, condensation temperature of refrigerant is assumed to be $45{ }^{\circ} \mathrm{C}$ which would be appropriate under summer outdoor design temperature. On the other hand, degree of subcooling and superheating are taken as $1^{\circ} \mathrm{C}$.

In figures 4 and 5 , variation of COP values with temperature are shown using R134a and R245fa as the working fluid, respectively. Efficiencies from literature are utilized for the calculations. Parameter in these figures is the exit pressure of the pump. It is seen that increasing pressure results in increasing COP values for both refrigerant. Besides, COP values decrease slowly with increasing temperature for R134a. 


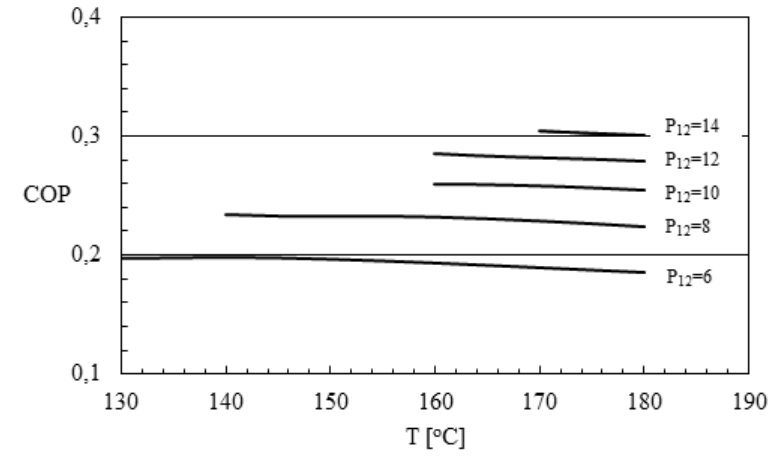

Figure 4. Variation of COP with temperature for different pressures for the refrigerant $\mathrm{R} 134 \mathrm{a}$

Results obtained using R245fa as the working fluid are similar to those obtained using R134a. Coefficient of performance values are a bit greater than those obtained utilizing R134a at the same operating conditions. However, unlike $\mathrm{R} 134 \mathrm{a}, \mathrm{COP}$ values tends to increase with increasing temperature at high pressures for refrigerant R245fa.

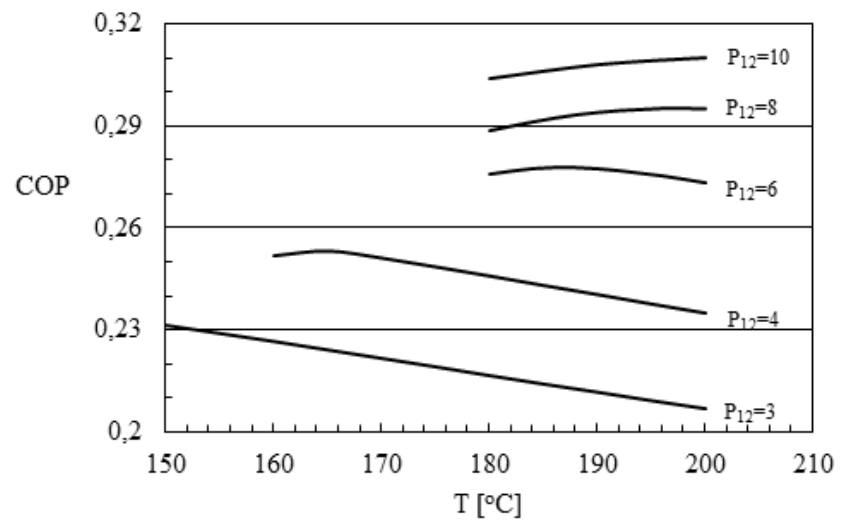

Figure 5. Variation of COP with temperature for different pressures for the refrigerant $\mathrm{R} 245 \mathrm{fa}$

Waste exhaust gas temperatures of heavy-duty diesel engines can be assumed in the range of $500-600{ }^{\circ} \mathrm{C}$ and corresponding waste heat energy amounts to till $400 \mathrm{~kW}$ $[18,21-23]$. It is seen that, modelled and simulated ejector refrigeration system can be used for air-conditioning of heavy vehicles with the utilization of engine's waste heat energy in exhaust gases even at low pump exit pressures and high temperatures.

\section{CONCLUSION}

Ejector refrigeration system is studied utilizing exhaust waste heat source for heavy vehicles air-conditioning. In addition to primary nozzle isentropic efficiencies, diffuser isentropic efficiencies and mixing efficiencies of the ejector; isentropic efficiency of the pump, total mechanical, coupling and electromotor efficiencies of the pump are taken into account for the analysis, utilizing different works in literature. Pump exit pressure is selected as parameter. The following conclusions can be drawn from this study:

- COP values increase up to $10 \mathrm{MPa}$ and $14 \mathrm{MPa}$ pressure for both R245fa and R134a, respectively.
- For R245fa, coefficient of performance values are a bit greater than those obtained utilizing R134a at the same operating condition.

- At low pump exit pressures, COP values are decreased after a certain temperature for both refrigerants.

- COP values tends to increase with increasing temperature at high pump exit pressure.

\section{ACKNOWLEDGEMENTS}

This work is supported by Çukurova University through Grant No. FBA-2015-3683

\section{REFERENCES}

[1] Zhao R., Zhuge W., Zhang Y., Yin Y., Chen Z., and Li Z. (2014) Parametric study of power turbine for diesel engine waste heat recovery. Appl. Therm. Eng., 67(1-2): 308-319, DOI: 10.1016/j.applthermaleng.2014.03.032.

[2] Dong J., Yu M., Wang W., Song H., Li C. and Pan X. (2017). Experimental investigation on low-temperature thermal energy driven steam ejector refrigeration system for cooling application. Applied Thermal Energy, 123: 167-176, DOI: 10.1016/j.applthermaleng.2017.05.061.

[3] Chen G., Volovyk O., lerin V. and Shestopalov K. (2017). Performance analysis of a two-stage mechanical compression-ejector cooling cycle intended for micro-trigeneration system. Int. J. Refrig., 81: 33-40, DOI: 10.1016/j.jijrefrig.2017.05.018.

[4] Ünal Ş., Erdinç M. T., and Kutlu Ç. (2017). Optimal thermodynamic parameters of two-phase ejector refrigeration system for buses. Appl. Therm. Eng., 124: 1354-1367, DOl: 10.1016/j.applthermaleng.2017.06.115.

[5] Khaliq A. (2015). Performance analysis of a waste-heat-powered thermodynamic cycle for multieffect refrigeration. Int. J. Energy Res., 39(4): 529-542, DOI: 10.1002/er.3269.

[6] Zhang H., Wang L., Yan J., Li X. and Wang L. (2017). Performance investigation of a novel EEV-based ejector for refrigerator- freezers. Appl. Therm. Eng., 121: 336-343, DOI: 10.1016/j.applthermaleng.2017.04.081.

[7] Aly N. H., Karameldin A., and Shamloul M. M. (1999). Modelling and simulation of steam jet ejectors. Desalination, 123(1): 1-8, DOI: 10.1016/S0011-9164(99)00053-3.

[8] Cizungu K., Mani A. and Groll M. (2011). Performance comparison of vapour jet refrigeration system with environment friendly working fluids. Appl. Therm. Eng., 21(5): 585-598, DOl:10.1016/ S13594311(00)00070-3.

[9] Dai Y., Wang J. and Gao L. (2009). Exergy analysis, parametric analysis and optimization for a novel combined power and ejector refrigeration cycle. Appl. Therm. Eng., 29(10): 1983-1990, DOI: 10.1016/j. applthermaleng.2008.09.016.

[10] Eames I. W., Aphornratana S. and Haider H. (1995). A theoretical and experimental study of a small-scale steam jet refrigerator. Int. J. Refrig., 18(6): 378-386, DOI: 10.1016/0140-7007(95)98160-m.

[11] Grazzini G., Milazzo A. and Paganini D. (2012). Design of an ejector cycle refrigeration system. Energy Convers. Manag., 54(1): 38-46, DOI: 10.1016/j.enconman.2011.09.015.

[12] Sun D.W. (1999). Comparative study of the performance of an ejector refrigeration cycle operating with various refrigerants. Energy Convers. Manag., 40(8): 873-884, DOI: 10.1016/s0196- 
8904(98)00151-4.

[13] Varga S., Oliveira A. C. and Diaconu B. (2009). Numerical assessment of steam ejector efficiencies using CFD. Int. J. Refrig., 32(6): 1203-1211, DOl: 10.1016/j.jirefrig.2009.01.007.

[14] Yu J.and Du Z. (2010). Theoretical study of a transcritical ejector refrigeration cycle with refrigerant R143a. Renew. Energy, 35(9): 2034-2039, DOI: 10.1016/j.renene.2010.02.004.

[15] Habibzadeh A., Rashidi M. M. and Galanis N. (2013). Analysis of a combined power and ejector-refrigeration cycle using low temperature heat. Energy Convers. Manag., 65: 381-391, DOI: 10.1016/j. enconman.2012.08.020.

[16] Little A. B. and Garimella S. (2011). Comparative assessment of alternative cycles for waste heat recovery and upgrade. Energy, 36(7): 4492-4504, DOI: 10.1016/j.energy.2011.03.069.

[17] Peris B., Navarro-Esbrí J. and Molés F. (2013). Bottoming organic Rankine cycle configurations to increase Internal Combustion Engines power output from cooling water waste heat recovery. Appl. Therm. Eng., 61(2): 364-371, DOl: 10.1016/j.applthermaleng.2013.08.016.

[18] Wang H., Peterson R. and Herron T. (2011). Design study of configurations on system COP for a combined ORC (organic Rankine cycle) and VCC (vapor compression cycle). Energy, 36(8): 4809-4820, DOI: 10.1016/j.energy.2011.05.015.

[19] ASHRAE Handbook (2007). Heating, Ventilating, and Air-Conditioning Applications (I-P Edition). Knovel.

[20] Arora R. C. (2010). Refrigeration and air conditioning.

[21] Çengel Y. A. and Boles M. A. (2008). Thermodynamics: an engineering approach

[22] Wang F., Shen S. Q., and Li D. Y. (2015). Evaluation on environment-friendly refrigerants with similar normal boiling points in ejector refrigeration system. Heat Mass Transf., 51(7): 965-972, DOI: 10.1007/s00231-014-1468-0.

[23] Armstead J. R. and Miers S. A. (2010). Review of Waste Heat Recovery Mechanisms for Internal Combustion Engines. Proc. Asme Intern. Combust. Engine Div. Fall Tech. Conf., 6: 965-974, DOl: $10.1115 / 1.4024882$ 